\title{
An Eighteen Year Study of Intestinal Protozoans in the Los Angeles Area Between 1996 and 2013
}

\author{
Omar M Amin ${ }^{*}$, Karim O Amin ${ }^{1}$ \\ ${ }^{1}$ Department of Parasitology, Parasitology Center, Inc. (PCI), Scottsdale, Arizona, United States
}

\section{Introduction}

Parasitological studies of large patient populations are rare in the United States compared to third-world countries where endemic parasitosis are more frequently reported (1). We routinely monitor and report the patterns and trends of human parasitosis in the US at the Parasitology Center, Inc. (PCI), in Scottsdale, Arizona. It was revealed that 916 (32\%) of 2896 examined patients from 48 states were infected with 19 species of intestinal parasites in the year 2000 (2). In that study, 314 of 859 examined patients (36\%) from California were found to be infected (2). Infections with helminth parasites such as Ascaris lumbricoides and non-pathogenic protozoans were rare; therefore, they were not included in the present study. The seven reported species of protozoan parasites constituted $91.5 \%$ of infections reported in the United States. Multiple infections with 2-4 parasitic species constituted $10 \%$ of the infected cases (2). We also investigated the epidemiology of Blastocystis hominis in 48 states and the District of Columbia in 2002-2004 and included trends in annual, seasonal, geographical and host distribution and symptomology by age, gender, and season (3). In that report, $16 \%$ of 10582 fecal specimens from 5291 patients tested positive for B. hominis; in California, 263 of 1,328 examined patients (20\%) were also positive for $B$. hominis. In a similar 3-year epidemiological study of 9856 fecal specimens from 4,928 patients from all states and the District of Columbia that we tested between 2003 and 2005, 279 (6\%) were positive for Cryptosporidium parvum infection. Studies of this magnitude have not been performed in the US. Few studies have been done on relatively large patient populations in the US $(4,5)$ or more geographically limited populations, which report the prevalence of $B$. hominis infection only in California (6) and Ontario (7). The present investigation is the first to cover a span of 18 years. Evaluating the patterns and trends of parasitic infections in studies of such a long duration is a great tool for understanding the epidemiological characteristics and disease burden, improving the reporting of cases, planning preventive

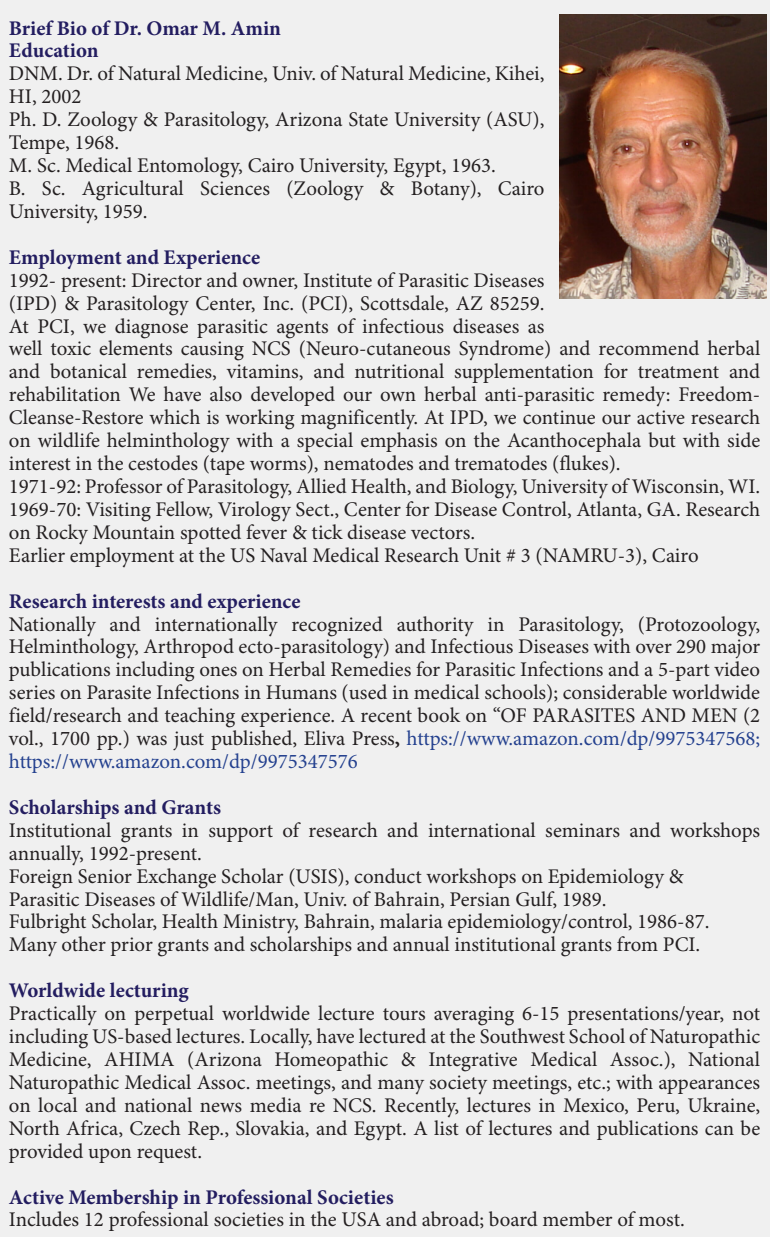

Active Membership in Professional Societie

Includes 12 professional societies in the USA and abroad; board member of most.

strategies, and designing therapeutic and public health measures in the management of these infections. Nevertheless, an overview of studies of shorter duration from comparable urban/suburban area in developing and developed nations are included.

In this study, seasonal and annual prevalence rates of intestinal protozoans were studied for a period of 18 years in an urban/suburban Los Angeles area for the first time in the world. A total of 7766 fecal specimens from 3883 patients in the Los Angeles County, from 1996 to 
2013 were tested at PCI, Scottsdale, Arizona. During this period, 1629 (41\%) patients were found to be infected with one or more protozoan parasites. The most prevalent parasites were Blastocystis hominis (19\%), Entamoeba histolytica/E. dispar (6\%), E. hartmanni (6\%), and Cryptosporidium parvum (5\%). Blastocystis hominis made up $45 \%$ of all infections. The prevalence of Blastocystis hominis infection progressively declined through 2013 while that of $C$. parvum infection increased. Infections with $B$. hominis were more prevalent in colder weather and the lowest prevalence was observed in August and September. Infections with C. parvum were the most prevalent from March to June and the lowest prevalence was observed in August. The overall monthly prevalence for all protozoan parasites varied between 34\% in August and $51 \%$ in February. The composition of the parasitic fauna diagnosed, annual prevalence rates, and seasonality were discussed in comparison with other studies.

\section{Conflict of Interests}

The authors declared that no competing interests exist.

\section{Ethical Issues}

Not applicable.

\section{References}

1. Amin OM. Prevalence and host relationships of intestinal protozoan infections during the summer of 1996. Explore. 1997;8(2):29-35.

2. Amin OM. Seasonal prevalence of intestinal parasites in the United States during 2000. Am J Trop Med Hyg. 2002;66(6):799-803. doi:10.4269/ajtmh.2002.66.799

3. Amin OM. The epidemiology of Blastocystis hominis in the United States. Res J Parasitol. 2006;1(1):1-10. doi:10.3923/ jp.2006.1.10

4. Kappus KD, Lundgren RG Jr, Juranek DD, Roberts JM, Spencer HC. Intestinal parasitism in the United States: update on a continuing problem. Am J Trop Med Hyg. 1994;50(6):705-713. doi:10.4269/ajtmh.1994.50.705

5. Church C, Neill A, Schotthoefer AM. Intestinal infections in humans in the Rocky Mountain region, United States. J Parasitol. 2010;96(1):194-196. doi:10.1645/ge-2229

6. Conteas CN, Berlin OG, Lariviere MJ, et al. Examination of the prevalence and seasonal variation of intestinal microsporidiosis in the stools of persons with chronic diarrhea and human immunodeficiency virus infection. Am J Trop Med Hyg. 1998;58(5):559-561. doi:10.4269/ ajtmh.1998.58.559

7. Senay H, MacPherson D. Blastocystis hominis: epidemiology and natural history. J Infect Dis. 1990;162(4):987-990. doi:10.1093/infdis/162.4.987

(C) 2021 The Author(s); This is an open-access article distributed under the terms of the Creative Commons Attribution License (http:// creativecommons.org/licenses/by/4.0), which permits unrestricted use, distribution, and reproduction in any medium, provided the original work is properly cited. 